\title{
Reuna
}

\section{MODELO ANALÍTICO PARA TRABALHOS CIENTÍFICOS À LUZ DO DISCURSO DA TEORIA CRÍTICA}

\section{ANALYTICAL MODEL OF SCIENTIFIC WORKS IN THE LIGHT OF THE CRITICAL THEORY'S SPEECH}

http://dx.doi.org/10.21714/2179-8834/2020v25n1p54-72

\author{
Gabriela Ostrovski Cabral \\ Universidade do Estado de Santa Catarina, Brasil. \\ E-mail: gabrielaostrovski@hotmail.com \\ Laleska Lebioda \\ Universidade do Estado de Santa Catarina, Brasil. \\ E-mail: laleskalebioda@hotmail.com \\ Luiz Filipe Goldfeder Reinecke \\ Universidade do Estado de Santa Catarina, Brasil. \\ E-mail: lipereinecke@gmail.com \\ Simone Ghisi Feuerschütte \\ Universidade do Estado de Santa Catarina, Brasil. \\ E-mail: ghisi.simone@gmail.com
}

Submissão: 26 Mar. 2020 Publicação: 4 Mai. 2020. Sistema de avaliação: Double blind review. Centro Universitário UNA, Belo Horizonte - MG, Brasil. Editor geral: Prof. Dr. Thiago Soares Nunes

Este artigo encontra-se disponível nos seguintes endereços eletrônicos:

http://revistas.una.br/index.php/reuna/article/view/1134

http://dx.doi.org/10.21714/2179-8834/2020v25n1p54-72

\section{Resumo}

O artigo apresenta uma proposta de modelo analítico para a condução de trabalhos científicos, no campo da Administração, à luz do discurso da Teoria Crítica, que visa contribuir para o fortalecimento do campo científico, por meio da promoção de coerência e consistência nas pesquisas acadêmicas. O modelo foi desenvolvido com base na literatura sobre o discurso da Teoria Crítica. Para exemplificar seu uso e testar o modelo, o mesmo foi aplicado em um trabalho acadêmico que utilizou-se deste discurso. Recomenda-se a ampliação do mesmo, com a inclusão de novos elementos relacionados ao discurso da Teoria Crítica, além da elaboração de modelos equivalentes sob outras vertentes epistemológicas e outros paradigmas/discursos da Administração, que possam auxiliar a condução de trabalhos científicos e fortalecer o campo, tais como o funcionalismo, interpretativismo, pós-modernismo e construtivismo.

Palavras-chave: Pesquisa em administração; Teoria Crítica; Modelo analítico; Epistemologia; Metodologia.

\section{Abstract}

The article presents an analytical model for conducting scientific work in the field of 
Administration, in light of the Critical Theory discourse. It aims to strengthen the scientific field by contributing to the promotion of coherence and consistency in academic research in the area. The model was developed based on the scientific literature on Critical Theory discourse. To exemplify its use and to test the model, it was applied. We recommend its expansion with the inclusion of new elements related to Critical Theory discourse, in addition to the elaboration of equivalent models under other epistemological aspects and other Administration paradigms/discourses that may help conduct scientific works and strengthen the field, such as functionalism, interpretivism, postmodernism, and constructivism.

Keywords: Administration research; Critical theory; Analytical model; Epistemology; Methodology.

\section{Introdução}

O campo da Administração, ainda nos dias atuais, é assombrado pelo questionamento de ser ou não uma ciência. Por mais que existam aqueles que a reconhecem como tal, mais especificamente como uma ciência social aplicada, existem discussões em aberto, sobretudo por pesquisadores das chamadas ciências duras, como por exemplo, a Física, de que a área não atende aos critérios de demarcação científica e, a consideram, por exemplo, como uma prática (SILVA; COSTA, 2019). Buscando a sua autonomia científica, o campo está em constante movimento na direção de construtos e critérios internos de legitimação, demarcação de fronteiras e diferenciação em relação a outras áreas.

A Administração se configura a partir das diferentes áreas que a sustentam, enquanto uma ciência aplicada interdisciplinar, e esta condição parece lhe atribuir uma identidade complexa, que faz com que tenha um olhar multifacetado da realidade, permitindo interpretações contextuais que, de certo modo, chancelam o seu viés de um campo dinâmico e sistemático, voltado à mudança, seja por meio de análises e reflexões dos contextos sobre os quais se debruça, seja através de proposições e intervenções concretas voltadas à transformação dos mesmos. O encaminhamento a ser dado por uma dessas trilhas, ou por ambas - o que expressa o caráter reflexivoanalítico, interpretativo e intervencionista da área, portanto, a práxis na Administração e sua legitimação - é orientado por escolhas teórico-epistemológicas de seus atores. Ou seja, a construção de critérios internos de legitimação e a autonomia científica no campo são orientados pela postura assumida pelos pesquisadores da área, por seus interesses ontológicos, pressupostos epistemológicos e pelo rigor metodológico adotado ao interagir com a realidade a ser apreendida (ALPERSTEDT; ANDION, 2017; CARDOSO, 2015).

Nesse sentido, se mostra válido para nós autores, contribuir com propostas que auxiliem na condução de pesquisas desenvolvidas sob diferentes perspectivas teórico-analíticas e vertentes epistemológicas e paradigmas/discursos diversos, tais como: funcionalismo, interpretativismo, pós-modernismo, construtivismo e complexidade. Ademais, se faz relevante na construção do conhecimento científico, particularmente na Administração, que os processos de pesquisa contemplem metodologias também diversas, considerando a realidade multifacetada e complexa sobre a qual se debruça o campo. 
A esse respeito, Maranhão e Vilela (2017), afirmam que os estudos organizacionais têm explorado os fundamentos da Teoria Crítica para analisar a realidade social (MONJE-REYES, 2015). Esses estudos, entretanto, concentram-se em modalidades de ensaio ou de artigos teóricos, levando à noção de que a Teoria Crítica parece não se aplicar em estudos empíricos. Os autores discutem a imanência entre a Teoria Crítica e a pesquisa empírica, evidenciando que a abordagem possa ser orientadora de estudos focalizados em evidências concretas da realidade, particularmente no âmbito das organizações e sua articulação com a sociedade (MARANHÃO; VILELA, 2017).

Em verdade, entendemos que o discurso da Teoria Crítica, dada a sua construção histórica e filosófica, se constitui em uma orientação que indica a reflexão sobre a realidade social, revelando o compromisso com a emancipação dos indivíduos e da sociedade, como sustentam Faria, Meneghetti e Stefani (2016). Os estudos teóricos contribuem para o avanço do conhecimento, quando baseados na perspectiva crítica, ao permitirem a elaboração de novos questionamentos, reflexões e críticas a temas já debatidos e resultantes de evidências empíricas (FARIA; MENEGHETTI; STEFANI, 2016). Complementarmente, a orientação teórica e epistemológica elaborada por autores da Teoria Crítica pode ser contrastada com expressões e práticas organizacionais, contribuindo, por exemplo para a compreensão de dinâmicas de poder e dominação e, a partir disso, auxiliando em processos de mudança nas relações entre dominados e dominantes (MONJE-REYES, 2015).

Nesse sentido, este artigo consiste em uma proposta de modelo analítico para a condução de trabalhos científicos, no campo da Administração, à luz do discurso da Teoria Crítica. Temos como pressuposto que tal modelo pode sustentar a visão de que a Teoria Crítica - por meio de seus princípios e sua construção epistemometodológica - permite o desvelamento da realidade social e, em específico, do mundo organizacional, em seus paradoxos e contradições, expostos em trabalhos científicos teóricos e teórico-empíricos.

Os pesquisadores críticos assumem que a realidade social é construída de forma histórica; buscam a liberdade, desvelando a dominação, lutando pela emancipação e transformação da sociedade (BATISTA-DOS-SANTOS, ALLOUFA, NEPOMUCENO, 2010; PAULA, 2015).

Desta forma, pretendemos contribuir para o fortalecimento do campo científico em Administração, defendendo a promoção de coerência e consistência nas pesquisas acadêmicas no que diz respeito ao caminho de investigação percorrido pelo pesquisador, uma vez que o trabalho científico deve guardar fidelidade à sua epistemologia e o processo de construção do conhecimento demonstrar consistência e singularidade (HILL, 1984, apud PAULA, 2015). A proposta do artigo, portanto, também é de auxiliar o pesquisador na perceção de eventuais contradições entre os elementos que estruturam o trabalho de investigação - os pressupostos teóricoanalíticos e as escolhas metodológico-técnicas. Como destaca Cardoso (2015, p. 106), "a postura do cientista durante todas as etapas de sua investigação deve ser tal que o rigor metodológico, aliado aos atributos de qualidade e ética permeie e faça parte de todo o seu trabalho científico".

A partir desta introdução, o artigo apresenta o referencial teórico que orientou o trabalho, com a descrição e contextualização do discurso da Teoria Crítica, cuja 
origem é a Escola de Frankfurt. Na sequência, apontamos o caminho percorrido para o desenvolvimento do modelo analítico, seguido de sua exposição. A quarta seção demonstra a aplicação do modelo analítico proposto, com a finalidade de explicar sua utilização; e, por fim, apresentamos as considerações finais.

\section{Escola de Frankfurt e a Teoria Crítica}

Em 1922, iniciou-se na Alemanha, a partir da iniciativa do economista e cientista social Félix Weil (1898-1975), apoiado por Friedrick Pollock e por Max Horkheimer, por ocasião da Primeira Semana de Trabalho Marxista em IImenau (Turingia), um movimento para a criação de um instituto que estudasse os fundamentos marxistas. Havia o estímulo, por parte dos professores da Universidade de Frankfurt, que tal instituto fosse associado à Universidade, mas que mantivesse autonomia intelectual e financeira (NOBRE, 2004).

O Institut für Sozialforschung - Instituto de Pesquisa Social - teve como seus primeiros membros Friedrick Pollock (economista e especialista em problemas de planejamento nacional), Carl August Wittfogel (sociólogo), Richard Sorge (jornalista), Henryk Grossmann (economista político) e Max Horkheimer (filósofo, sociólogo e psicólogo social). No final dos anos de 1930, Erich Fromm (psicanalista e psicólogo social), Franz Neumann (cientista político), Herbert Marcuse (filósofo), Leo Lowenthal (estudioso da cultura popular e da literatura), Otto Kirchheimer (cientista político) e Theodor Wiesengrand-Adorno (filósofo, sociólogo e musicólogo), se integraram ao grupo, fortalecendo o movimento e a organização do referido Instituto (BOTTOMORE, 2012).

Vale ressaltar, a partir da diversidade de seus integrantes, que a constituição do Instituto de Pesquisa Social foi influenciada fortemente pelo contexto histórico, à época, o qual demarcou também o seu perfil inicial. Conforme Bottomore (2012, p.208),

"[...] a derrota dos movimentos proletários de esquerda na Europa Ocidental após a Primeira Guerra Mundial, o colapso dos partidos de massa de esquerda na Alemanha, que se transformaram em movimentos ou reformistas ou dominados por Moscou, a degeneração da revolução russa com o stalinismo e a ascensão do fascismo e do nazismo",

foram acontecimentos marcantes ocorridos no período de criação Instituto de Pesquisa Social (BOTTOMORE, 2012).

Criado oficialmente em fevereiro de 1923, o objetivo principal do Instituto era realizar investigações científicas com base nas obras de Karl Marx (1818-1883). A partir de 1930, Horkheimer se torna diretor do Instituto, dando-Ihe uma nova roupagem, com a inovação em termos de trabalho coletivo interdisciplinar, abrangendo a Economia, a Ciência Política e a Psicologia, de forma que pesquisadores de diferentes especialidades trabalhassem em conjunto, porém mantendo a referência comum à tradição marxista. Essa experiência inovadora ficou conhecida como "materialismo interdisciplinar" e, para expressar esse novo pensamento do Instituto, Horkheimer editou a Zeitschrift für Sozialforschung - Revista de Pesquisa Social (NOBRE, 2004).

O termo Escola de Frankfurt surge somente na década de 1950, mesma época em que Theodor Adorno assume a direção da Escola. $O$ pensamento dos 
pesquisadores da Escola de Frankfurt sofreu influência da filosofia alemã, a partir de Kant, Fichte, Schelling, Hegel e Schopenhauer na primeira fase, conhecida como o idealismo alemão clássico (séc. XVIII até 1860); Karl Marx e Friedrich Engels na segunda fase, com o materialismo dialético; e Nietzsche na terceira fase. Além desses, novos diálogos aconteceram com outros pensadores, como Max Weber (WEBERING, 2010).

Em relação às gerações que constituíram a Escola de Frankfurt, verifica-se as diferentes fases de pensamento e seus temas centrais de estudo. A primeira geração teve como principais pensadores Erich Fromm (1900-1980), Friedrich Pollock (18941970), Herbert Marcuse (1898-1979), Max Horkheimer (1895-1973), Theodor Adorno (1903-1969), Walter Benjamin (1892-1940), dentre outros. As principais obras desta fase foram: A Dialética do Esclarecimento (ADORNO; HORKHEIMER, 1985), Eros e Civilização (MARCUSE, 2017) e O Homem Unidimensional (MARCUSE, 2015). Já os temas centrais de estudo se referiam a análise da dominação e a emancipação, a indústria cultural, a dialética do esclarecimento e a dialética negativa, a crítica à teoria tradicional e o desenvolvimento de uma Teoria Crítica (BOTTOMORE, 2012), esta última constituindo-se o foco deste artigo.

A Teoria Crítica possui como base as obras de Karl Marx (1818-1883) (MARX, 2012; 2015a; 2015b; 2017a; 2017b.; MARX; ENGELS, 2015; 2017) e é sustentada em princípios fundamentais. O primeiro princípio é o da orientação para a emancipação, que torna possível a compreensão da sociedade em seu conjunto. Seu segundo princípio fundamental é o do comportamento crítico, de forma que o exame da realidade ocorra a partir do critério da distância, permitindo não apenas identificar as potencialidades, mas também os obstáculos à emancipação presentes em cada momento histórico (NOBRE, 2004).

Logo, o discurso da Teoria Crítica tem por atributos o questionamento e a transformação da sociedade, pautada por fundamentações teóricas, não se tratando de um conjunto de regras, mas pela sua característica questionadora busca não somente entender a realidade, mas modificá-la em prol do desenvolvimento coletivo (FARIA, 2007). Como explicado por Pinzani (2017), com base em Horkheimer, enquanto a teoria tradicional se interessa em explicações pragmáticas por meio da ordenação e classificação de dados tidos como naturais e imutáveis, a Teoria Crítica volta-se à emancipação e à transformação da realidade social.

Para Faria (2007), a Teoria Crítica é constituída do pensamento radical, da fuga à subversão da razão e da busca do humanismo. O autor explicita seis categorias gerais que a caracterizam:

a) Contradições: os fatos se transformam, sendo as contradições consequências da própria história, que se desenrola no tempo dependendo das condições materiais de existência;

b) Ideologia dominante: a ideologia é vista como fragmentadora da compreensão da totalidade, de forma que o indivíduo não enxerga o fato real, beneficiando alguns grupos ou classes;

c) Racionalidades dominantes: são criadas para que práticas exploradoras não sejam percebidas, legitimando ideias e valores a fim de manter privilégios de determinados grupos sociais; 
d) Contexto social histórico: corresponde a um conjunto de elementos à sua época, como condições materiais, graus de consciência distintos, conhecimentos específicos sobre determinados assuntos, concepções morais diferenciadas, etc. que, atrelados à trajetória histórica, darão o entendimento do fato social;

e) Emancipação: é a busca pela autonomia do indivíduo e da sociedade através do desempenho ativo dos indivíduos em relação a problemas que afetem 0 coletivo, superando a alienação, a reificação e a opressão;

f) Conscientização individual e coletiva: A consciência não está relacionada com ter ciência de si próprio apenas pela razão. É fundamental o amparo dos sentimentos e da emoção para a consciência de si e dos outros, e a compreensão da realidade se mostra como fator preponderante para esse processo. O coletivo é a melhor forma de se apropriar do real, pois através do debate, do diálogo, da capacidade coletiva de pensar são incrementadas condições de apreender a realidade.

A Teoria Crítica, portanto, visa a emancipação dos indivíduos (RUFFINI, 2017; ALLEN, 2017) e a prevalência dos interesses coletivos sobre os individuais, de forma que sejam protagonistas das suas histórias, mas que as escrevam coletivamente, conscientes das suas responsabilidades e das suas atribuições coletivas, sendo capazes de indagar e questionar as ações. Nesse sentido, a Teoria fundamenta-se no materialismo histórico e dialético, na práxis dos sujeitos, no processo coletivamente construído, na interação do sujeito com o real e na dinâmica dos acontecimentos (FARIA, 2007; NOVAES NETTO et al., 2016).

Dentre os interesses dos teóricos clássicos do discurso da Teoria Crítica, encontram-se a compreensão da estrutura do mercado, a organização da sociedade, a distribuição do poder político e da riqueza, a forma do Estado e o papel da família e da religião. O propósito de seus adeptos é denunciar a repressão e o controle social, por entenderem que uma sociedade que se fundamenta em princípios de justiça, liberdade e democracia só se torna possível quando livre da exploração (NOBRE, 2004).

Após o surgimento da Teoria Crítica desponta a segunda geração da Escola de Frankfurt, que se inicia com a morte de Adorno. O principal representante da segunda geração foi Jurgen Habermas, até então assistente de Adorno, que passa a ser o seu crítico mais ferrenho. Habermas tem uma fase de trabalhos vinculada à primeira geração, mas depois distancia-se do marxismo e propõe o desenvolvimento da ação comunicativa. Por fim, a terceira geração da Teoria Crítica tem como objeto de estudo a luta pelo reconhecimento na perspectiva crítica hegeliana. O principal representante dessa geração é Axel Honneth, que faz um retorno crítico às gerações anteriores (NOBRE, 2004).

$\mathrm{Na}$ contemporaneidade, os estudos a partir da Teoria Crítica ampliam as perspetivas tradicionais, apontando olhares para além da Escola de Frankfurt, buscando explorar aspectos que levem à renovação do respectivo campo teórico Domingues (2019) destaca uma vertente da Teoria Crítica que questiona a modernidade não se sustentando apenas nos valores contrários às instituições de dominação, mas àqueles voltados à mobilização dos atores que vislumbram e levam adiante a busca pela emancipação prometida. Para o autor a compreensão do universo contemporâneo, expresso em problemas sociais concretos e as práticas sociais precisam ser abordados pela Teoria Crítica: "La teoría crítica [...] puede y debe 
renovarse, de modo de lidiar con las grandezas y miserias de la modernidad contemporánea, y contribuir para reencontrar las avenidas del cambio social progresista" (DOMINGUES, 2019, p.118).

\section{O caminho percorrido para a elaboração do modelo analítico}

Tal como já destacado, este artigo constitui-se de uma proposta de modelo analítico para a condução de trabalhos científicos, no campo da Administração, à luz do discurso da Teoria Crítica. A criação do modelo surgiu com o intuito de contribuir para a promoção de coerência e consistência epistemológica nas pesquisas acadêmicas elaboradas na referida Teoria, no que diz respeito ao caminho de investigação percorrido pelo pesquisador. Deste modo, contribui para que o pesquisador, ao conduzir uma pesquisa à luz do discurso da Teoria Crítica, observe se o trabalho aponta contradições, ou não, entre seus elementos.

Nessa perspectiva, iniciamos a elaboração do modelo pelo resgate de elementos teóricos-epistemológicos de pesquisas científicas no campo da Administração. Tal busca resultou na identificação de cinco elementos centrais, quais sejam: 1) paradigma; 2) ontologia; 3) epistemologia (naturalização versus história, sistema versus práxis social, dominação/alienação versus emancipação); 4) relação sujeito-objeto; e 5) metodologia (natureza da pesquisa, técnicas de pesquisa, compreensão dos resultados) (DEMO, 1985).

Após este levantamento, o segundo momento para a elaboração do modelo analítico envolveu a busca pela definição dos elementos teóricos-epistemológicos relacionados, no que tange ao discurso da Teoria Crítica. Utilizou-se como ponto de partida o artigo "Epistemologia e Metodologia para as pesquisas em administração: leituras aproximadas de Horkheimer e Adorno", de Batista-dos-Santos, Alloufa e Nepomuceno (2010).

Além deste trabalho, a elaboração do modelo se sustentou em elementos contidos em artigos científicos do campo da Administração que abordavam estudos da Escola de Frankfurt (FARIA, MARANHÃO, MENEGHETTI, 2013; MARANHÃO; VILELA, 2017) e/ou obras que abordavam estudos do discurso da Teoria Crítica no campo da Administração (WEBERING, 2010; PAULA, 2015; NOVAES NETTO et al., 2016). Ainda, utilizou-se como referencial para o desenvolvimento do modelo trabalhos teórico-empíricos desenvolvidos com base em metodologias de pesquisa em discurso da Teoria Crítica aplicados à Administração (MARANHÃO, VILELA, 2010; SALLES, 2014; MONJE-REYES, 2015; MARANHÃO; VILELA, 2017).

Diante do exposto, apresenta-se no Quadro 1, o modelo analítico desenvolvido, na sua versão final. 


\begin{tabular}{|c|c|c|}
\hline Elementos & Descrição do elemento & $\begin{array}{l}\text { Análise } \\
\text { do } \\
\text { trabalho }\end{array}$ \\
\hline $\begin{array}{l}\text { 1. Paradigma } \\
\text { (abordagem } \\
\text { sociológica) }\end{array}$ & $\begin{array}{l}\text { Abordagem Humanista Radical, trazendo a pergunta: "as } \\
\text { coisas precisam realmente ser como são?" (PAULA, 2015, p. } \\
\text { 154). Esta abordagem paradigmática tem como objetivo realizar } \\
\text { uma crítica ao funcionalismo, porém não somente com caráter } \\
\text { denunciativo (estruturalismo), mas sim emancipatório, } \\
\text { reforçando o papel do homem como ser histórico e transformador } \\
\text { (PAULA, 2015). }\end{array}$ & \\
\hline 2. Ontologia & $\begin{array}{l}\text { Ontologia materialista, buscando-se uma compreensão } \\
\text { histórica (BATISTA-DOS-SANTOS, ALLOUFA, NEPOMUCENO, } \\
\text { 2010). A visão dialética de sociedade, focando na emancipação } \\
\text { e transformação do todo (PAULA, 2015). A realidade como devir, } \\
\text { movimento, fluxo. (ANDION; CAMINHA, 2017). }\end{array}$ & \\
\hline 3. Epistemologia & $\begin{array}{l}\text { Epistemologia tem como base três elementos: o alinhamento } \\
\text { com a filosofia negativa, a preferência pelo interesse } \\
\text { emancipatório e o uso da dialética (PAULA, 2015). }\end{array}$ & \\
\hline $\begin{array}{l}\text { 3.1. Naturalização } \\
\text { versus História }\end{array}$ & $\begin{array}{l}\text { Nas teorias tradicionais há uma naturalização, ou seja, o objeto } \\
\text { está dado e o homem busca somente compreendê-lo. No } \\
\text { discurso da Teoria Crítica existe a perspectiva histórica, ou } \\
\text { seja, não existe esta previsibilidade do objeto. Os fatos são pré- } \\
\text { formados pelo caráter histórico do objeto percebido, bem como o } \\
\text { caráter histórico do órgão perceptivo (BATISTA-DOS-SANTOS, } \\
\text { ALLOUFA, NEPOMUCENO, 2010). }\end{array}$ & \\
\hline $\begin{array}{l}\text { 3.2. Sistema versus } \\
\text { Práxis Social }\end{array}$ & $\begin{array}{l}\text { Na perspectiva tradicional existe sistema teórico livre de } \\
\text { contradições e uma tendência harmonizadora. Utilizando seus } \\
\text { métodos mecânicos desaparecem os antagonismos da } \\
\text { realidade. O método lógico da redução elimina virtualmente as } \\
\text { contradições. Pode-se deduzir toda e qualquer coisa. O resultado } \\
\text { é um sistema unificado. Na perspectiva do discurso da Teoria } \\
\text { Crítica constata-se que há parcialidade, ou seja, existe } \\
\text { contradição, colocada como "contradição dialética" no qual seu } \\
\text { objetivo é expor os antagonismos reais. Não se busca uma visão } \\
\text { definitiva da totalidade social, tendo a práxis social como } \\
\text { dimensão central para análise demonstrando seus antagonismos } \\
\text { que emergem no devir histórico (BATISTA-DOS-SANTOS, } \\
\text { ALLOUFA, NEPOMUCENO, 2010). }\end{array}$ & \\
\hline $\begin{array}{l}\text { 3.3. } \\
\text { Dominação/Alienação } \\
\text { versus Emancipação }\end{array}$ & $\begin{array}{l}\text { Nas teorias tradicionais o que o homem busca é aprender sobre } \\
\text { a natureza para domina-la completamente. Existe uma "ilusão de } \\
\text { liberdade", na verdade tencionando o homem para a alienação. } \\
\text { No discurso da Teoria Crítica o que se busca é a liberdade, } \\
\text { lutando pela transformação do todo (emancipação). Busca-se } \\
\text { desvelar a dominação. Ser um pessimista teórico, mas sempre } \\
\text { um otimista prático (BATISTA-DOS-SANTOS, ALLOUFA, } \\
\text { NEPOMUCENO, 2010). }\end{array}$ & \\
\hline
\end{tabular}




Quadro 1 - Modelo analítico para a condução de trabalhos científicos, à luz do
discurso da Teoria Crítica (conclusão)

Fonte: Elaborado com base em Batista-dos-Santos, Alloufa, Nepomuceno, 2010; Maranhão, Vilela, 2010; Webering, 2010; Faria, Maranhão, Meneghetti, 2013; Salles, 2014; Paula, 2015; Andion, Caminha, 2017.

Importante salientar que este modelo analítico não se limita a servir como um check-list que auxiliará o usuário do modelo a responder "sim" ou "não" sobre a presença ou ausência de elementos teórico-epistemólogicos. Trata-se de um modelo de apoio, no qual se permite inserir extratos do texto que está sendo desenvolvido, ou mesmo análises, para o caso de o texto não apresentar explicitamente o que está se buscando analisar.

O fato de os fundamentos teórico-epistemológicos não estarem explícitos no texto sob análise, não significa que o mesmo seja isento de escolhas que mostrem o olhar e o "compromisso" do pesquisador com o fenômeno, ou seja, que ele não expresse uma ontologia e epistemologia. Sobre tal ponto Michael Hill (1984, apud PAULA, 2015) apresenta a proposta de "escavação", recurso utilizado para entender a amarração do trabalho com os seus diversos elementos constitutivos, como: visão de mundo metacientífico, metodologias e teorias. 
Da mesma forma, reforça-se que os elementos apresentados pelo modelo são um conjunto de características e pressupostos que visam contribuir para a condução de trabalhos científicos à luz do discurso da Teoria Crítica, sem limitar o pesquisador em sua investigação, mas oferecendo subsídios teóricos-epistemólogicos para a consistência e coerência de sua pesquisa.

Ao compreender a epistemologia como um tipo de discurso no campo da ciência (JAPIASSU, 1991), qualquer texto científico trará consigo um discurso que partirá do cientista, e este, segundo Demo (1985), irá expressar uma visão de mundo, ou seja, uma ontologia. Portanto, é importante que o pesquisador, ao buscar a orientação do modelo analítico aqui proposto, o entenda como um instrumento de auxílio para compreender o "quebra-cabeças" implícito no trabalho científico.

Assim, no momento da análise do trabalho científico em condução, é importante situar o que foi explicitamente colocado no trabalho, com trechos do texto, bem como o que se compreende, implicitamente, através da escavação e comparação entre as partes do trabalho. Se faz necessário verificar sua coerência argumentativa, visto que a maior crítica aos estudos desta matriz é seu caráter relativista e particular, debate este infindável pelos cientistas das ciências duras que situam, como traria Kuhn (2015), as ciências sociais como pré-paradigmáticas.

À título de ilustração, o próximo tópico apresenta a aplicação do modelo analítico proposto, com a finalidade de ilustrar sua utilização.

\section{Aplicação do modelo analítico}

O modelo proposto se dispõe a colaborar com a condução de trabalhos científicos, no campo da Administração, à luz do discurso da Teoria Crítica. A fim de verificar a utilidade do modelo, nesta seção expomos sua aplicação. O modelo foi aplicado em um trabalho finalizado - uma dissertação de Mestrado em Administração. Apresentamos um resumo do trabalho acadêmico analisado, porém preservamos a sua autoria.

A dissertação escolhida teve como objetivo comparar e analisar o autoritarismo entre gerentes e trabalhadores operacionais de empresas industriais e de prestação de serviços, a partir da aplicação de um instrumento quantitativo. O referencial teórico apresentou conceitos relacionados ao autoritarismo e ao comportamento autoritário a partir da Teoria Crítica da Escola de Frankfurt. O autor apresentou o desenvolvimento da escala utilizada e, em seguida, a sua aplicação junto a gerentes e trabalhadores operacionais. Conclui que há uma tendência, em todos os grupos, de expressarem níveis semelhantes de autoritarismo, exceto pelos gerentes do setor industrial, que apresentaram níveis estatisticamente significativos inferiores aos demais.

Desta forma, seguindo as orientações apontadas no capítulo anterior, o Quadro 2, a seguir, apresenta a aplicação do modelo analítico. A primeira coluna expõe o elemento da pesquisa científica; a segunda coluna oferece a descrição do elemento analisado, considerando o discurso da Teoria Crítica; por fim, a terceira coluna apresenta uma breve análise do tópico avaliado, com trechos do trabalho para como ilustração, quando possível. 
Quadro 2 - Exemplo de aplicação do modelo analítico proposto (continua)

\begin{tabular}{|c|c|c|}
\hline Elementos & Descrição do elemento & Análise do trabalho \\
\hline $\begin{array}{l}\text { 1. Paradigma } \\
\text { (Abordagem } \\
\text { sociológica) }\end{array}$ & $\begin{array}{l}\text { Abordagem Humanista Radical } \\
\text { trazendo a pergunta: "as coisas } \\
\text { precisam realmente ser como são?" } \\
\text { (PAULA, 2015, p. 154). Esta abordagem } \\
\text { paradigmática tem como objetivo } \\
\text { realizar uma crítica ao funcionalismo, } \\
\text { porém não somente com caráter } \\
\text { denunciativo (estruturalismo), mas sim } \\
\text { emancipatório, reforçando o papel do } \\
\text { homem como ser histórico e } \\
\text { transformador (PAULA, 2015). }\end{array}$ & $\begin{array}{l}\text { Análise: O autor situa a discussão de } \\
\text { seu trabalho no discurso da Teoria } \\
\text { Crítica dentro do paradigma Humanista } \\
\text { Radical, porém analisando o trabalho } \\
\text { verifica-se maior aderência à } \\
\text { abordagem funcionalista. } \\
\text { Trecho do trabalho: A Teoria Crítica foi } \\
\text { desenvolvida pelos autores } \\
\text { identificados como pertencendo ao que } \\
\text { ficou conhecido como Escola de } \\
\text { Frankfurt, enquadrada no trabalho de } \\
\text { Burrel e Morgan (1979) dentro do } \\
\text { paradigma radical humanista. }\end{array}$ \\
\hline 2. Ontologia & $\begin{array}{l}\text { Ontologia materialista, buscando-se } \\
\text { uma compreensão histórica (BATISTA- } \\
\text { DOS-SANTOS, ALLOUFA, } \\
\text { NEPOMUCENO, 2010). A visão } \\
\text { dialética de sociedade, focando na } \\
\text { emancipação e transformação do todo } \\
\text { (PAULA, 2015). A realidade como devir, } \\
\text { movimento, fluxo. (ANDION; CAMINHA, } \\
\text { 2017). }\end{array}$ & $\begin{array}{l}\text { Análise: O autor apresenta a ontologia } \\
\text { materialista na introdução do trabalho, } \\
\text { porém no desenvolvimento da própria } \\
\text { dissertação através da escavação nota- } \\
\text { se que a ontologia do autor é objetivista, } \\
\text { visto na escolha metodológica e na } \\
\text { análise dos resultados. Ela cita } \\
\text { inicialmente a historicidade, porém parte } \\
\text { de uma visão de simples descrição da } \\
\text { realidade. } \\
\text { Trecho do trabalho: A questão é que } \\
\text { os temas que têm como parte de seu } \\
\text { conteúdo questões relacionadas com a } \\
\text { personalidade são naturalmente } \\
\text { complexas e extensas, em função dos } \\
\text { diversos enfoques que a ele podem } \\
\text { estar ligados, e que são determinados } \\
\text { pelas origens (histórica, cultural, } \\
\text { econômica e social) de quem o aborda. }\end{array}$ \\
\hline 3.Epistemologia & $\begin{array}{l}\text { Epistemologia tem como base três } \\
\text { elementos: o a alinhamento com a } \\
\text { filosofia negativa, a preferência pelo } \\
\text { interesse emancipatório e o uso da } \\
\text { dialética (PAULA,2015). }\end{array}$ & $\begin{array}{l}\text { Análise: O autor apenas situa a } \\
\text { pesquisa dentro do discurso da Teoria } \\
\text { Crítica, vinculando-a a Escola de } \\
\text { Frankfurt e principalmente a Adorno, } \\
\text { sem desenvolver no restante do } \\
\text { trabalho essa visão. Nas considerações } \\
\text { finais se aproxima da discussão sobre } \\
\text { emancipação. } \\
\text { Na introdução o autor traz uma visão } \\
\text { majoritariamente funcionalista, } \\
\text { percebida no trecho do trabalho: } \\
\text { subsidiar critérios para recrutamento e } \\
\text { seleção para os indivíduos nas } \\
\text { organizações. }\end{array}$ \\
\hline
\end{tabular}




\section{Quadro 2 - Exemplo de aplicação do modelo analítico proposto (continua)}

\begin{tabular}{|c|c|c|}
\hline Elementos & Descrição do elemento & Análise do trabalho \\
\hline $\begin{array}{l}3.1 . \\
\text { Naturalização } \\
\text { versus História }\end{array}$ & $\begin{array}{l}\text { Nas teorias tradicionais há uma naturalização, } \\
\text { ou seja, o objeto está dado e o homem busca } \\
\text { somente compreendê-lo. No discurso da } \\
\text { Teoria Crítica existe a perspectiva histórica, } \\
\text { ou seja, não existe esta previsibilidade do } \\
\text { objeto. Os fatos são pré-formados pelo caráter } \\
\text { histórico do objeto percebido, bem como o } \\
\text { caráter histórico do órgão perceptivo } \\
\text { (BATISTA-DOS-SANTOS, } \\
\text { NEPOMUCENO, 2010). }\end{array}$ & $\begin{array}{l}\text { Análise: } O \text { autor se utiliza de } \\
\text { teorias tradicionais naturalizando } \\
\text { o objeto de pesquisa. Em seu } \\
\text { objetivo geral, como em sua } \\
\text { análise, o autor expõe a realidade } \\
\text { como dada, demonstrando } \\
\text { previsibilidade. Não aborda a } \\
\text { perspectiva histórica. } \\
\text { Trecho do trabalho: Objetivo } \\
\text { geral de identificar e comparar os } \\
\text { graus de autoritarismo de } \\
\text { operários e de gerentes de } 4^{\circ} \text { nível } \\
\text { de empresas do estado X. }\end{array}$ \\
\hline $\begin{array}{l}\text { 3.2. Sistema } \\
\text { versus Práxis } \\
\text { Social }\end{array}$ & $\begin{array}{l}\text { Na perspectiva tradicional existe sistema teórico } \\
\text { livre de contradições e uma tendência } \\
\text { harmonizadora. Utilizando seus métodos } \\
\text { mecânicos desaparecem os antagonismos da } \\
\text { realidade. O método lógico da redução elimina } \\
\text { virtualmente as contradições. Pode-se deduzir } \\
\text { toda e qualquer coisa. O resultado é um } \\
\text { sistema unificado. Na perspectiva do } \\
\text { discurso da Teoria Crítica constata-se que há } \\
\text { parcialidade, ou seja, existe contradição, } \\
\text { colocada como "contradição dialética" no qual } \\
\text { seu objetivo é expor os antagonismos reais. } \\
\text { Não se busca uma visão definitiva da totalidade } \\
\text { social, tendo a práxis social como dimensão } \\
\text { central para análise demonstrando seus } \\
\text { antagonismos que emergem no devir histórico } \\
\text { (BATISTA-DOS-SANTOS, ALLOUFA, } \\
\text { NEPOMUCENO, 2010). }\end{array}$ & $\begin{array}{l}\text { Análise: O autor expõe apenas a } \\
\text { contradição entre o que era } \\
\text { previsto teoricamente com o que } \\
\text { se apresenta com a aplicação da } \\
\text { escala RWA, porém não } \\
\text { aprofunda o antagonismo nem o } \\
\text { relaciona ao devir histórico. } \\
\text { Trecho do trabalho: Entretanto, } \\
\text { seria, a estrutura a única } \\
\text { explicação possível para as } \\
\text { relações autoritárias nas } \\
\text { organizações? }\end{array}$ \\
\hline
\end{tabular}

(continua) 
Quadro 2 - Exemplo de aplicação do modelo analítico proposto (continua)

\begin{tabular}{|c|c|c|}
\hline Elementos & Descrição do elemento & Análise do trabalho \\
\hline $\begin{array}{c}3.3 . \\
\text { Dominação/ } \\
\text { Alienação } \\
\text { versus } \\
\text { Emancipação }\end{array}$ & $\begin{array}{l}\text { Nas teorias tradicionais o que o homem } \\
\text { busca é aprender sobre a natureza para } \\
\text { domina-la completamente. Existe uma } \\
\text { "ilusão de liberdade", na verdade } \\
\text { tencionando o homem para a alienação. } \\
\text { No discurso da Teoria Crítica o que se } \\
\text { busca é a liberdade, lutando pela } \\
\text { transformação do todo (emancipação). } \\
\text { Busca-se desvelar a dominação. Ser um } \\
\text { pessimista teórico, mas sempre um } \\
\text { otimista prático (BATISTA-DOS- } \\
\text { SANTOS, ALLOUFA, NEPOMUCENO, } \\
\text { 2010). }\end{array}$ & $\begin{array}{l}\text { Análise: O objetivo da pesquisa foi } \\
\text { somente analisar e comparar. Mesmo } \\
\text { trazendo em suas considerações finais } \\
\text { afirmações como a exposta no trecho a } \\
\text { seguir, o autor não desenvolveu o caráter } \\
\text { emancipatório. } \\
\text { Trecho do trabalho: Pode-se pensar } \\
\text { que, sendo esses comportamentos } \\
\text { desejáveis para trabalhadores } \\
\text { enquadrados em uma estrutura } \\
\text { hierárquica de uma organização } \\
\text { burocrática, a identificação de aspectos } \\
\text { da personalidade que predisponham a } \\
\text { um comportamento autoritário possa ser } \\
\text { útil em processos de recrutamento e } \\
\text { seleção nas organizações que tenham } \\
\text { esse perfil. Isto, do ponto de vista do } \\
\text { positivismo utilitarista na gestão, quando } \\
\text { esta está calcada no que se poderia } \\
\text { sintetizar no ditado manda quem pode, } \\
\text { obedece quem tem juízo, próprio de um } \\
\text { Brasil de tradição histórica escravocrata } \\
\text { e autoritária, e que tem ainda esse como } \\
\text { o estilo de gestão largamente } \\
\text { predominante. }\end{array}$ \\
\hline $\begin{array}{c}\text { 4. Relação } \\
\text { Sujeito-Objeto }\end{array}$ & $\begin{array}{l}\text { Noção de totalidade, onde o sujeito e } \\
\text { objeto existem tão somente em situação } \\
\text { de relação. As partes são constituídas do } \\
\text { todo e formadoras do todo, possuem um } \\
\text { movimento próprio articulado na } \\
\text { totalidade, sem a ela se reduzir } \\
\text { (BATISTA-DOS-SANTOS, ALLOUFA, } \\
\text { NEPOMUCENO, 2010). A sociedade é } \\
\text { sujeito e objeto ao mesmo tempo } \\
\text { (PAULA, 2015). }\end{array}$ & $\begin{array}{l}\text { Análise: Existe uma relação sujeito- } \\
\text { objeto e uma neutralidade do } \\
\text { pesquisador com o objeto de estudo. } \\
\text { Não fica claro a afirmação de que a } \\
\text { sociedade é sujeito e objeto ao mesmo } \\
\text { tempo. }\end{array}$ \\
\hline 5. Metodologia & $\begin{array}{l}\text { 1) A realidade é sempre maior do que } \\
\text { podemos perceber. } \\
\text { 2) Todas as fases da pesquisa são inter- } \\
\text { relacionadas, não podendo trabalha-las } \\
\text { de forma isolada e fragmentada } \\
\text { (BATISTA-DOS-SANTOS, ALLOUFA, } \\
\text { NEPOMUCENO, 2010). }\end{array}$ & $\begin{array}{l}\text { Análise: } \\
\text { 1) Nas limitações do trabalho o autor } \\
\text { deixa explicito sua intencionalidade em } \\
\text { generalizar. } \\
\text { 2) Não se aplica, muitas fases da } \\
\text { pesquisa foram feitas de forma isolada. }\end{array}$ \\
\hline
\end{tabular}

(continua) 
Quadro 2 - Exemplo de aplicação do modelo analítico proposto (conclusão)

\begin{tabular}{|c|c|c|}
\hline Elementos & Descrição do elemento & Análise do trabalho \\
\hline $\begin{array}{l}\text { 5.1. Natureza } \\
\text { da Pesquisa }\end{array}$ & $\begin{array}{lr}\text { Trabalhos de natureza } & \text { qualitativa } \\
\text { (BATISTA-DOS-SANTOS, } & \text { ALLOUFA, } \\
\text { NEPOMUCENO, 2010; } & \text { FARIA, } \\
\text { MARANHÃO, MENEGHETTI, 2013). }\end{array}$ & $\begin{array}{l}\text { Análise: O próprio autor, em suas } \\
\text { conclusões, reconhece que a melhor } \\
\text { abordagem para estudos que utilizem o } \\
\text { discurso da Teoria Crítica é a qualitativa. } \\
\text { Nas limitações do trabalho o autor expõe } \\
\text { que o trabalho não teve aprofundamento } \\
\text { pela utilização somente de métodos } \\
\text { quantitativos. } \\
\text { Trecho do trabalho: A abordagem } \\
\text { escolhida é a quantitativa, uma vez que } \\
\text { será utilizada uma escala, a RWA, de } \\
\text { Altemeyer (1981), baseada na escala "F" } \\
\text { de Adorno (1982). }\end{array}$ \\
\hline $\begin{array}{l}\text { 5.2. Técnicas } \\
\text { de Pesquisa }\end{array}$ & $\begin{array}{l}\text { Técnicas de entrevista (com elementos } \\
\text { de história de vida, com questão } \\
\text { estímulo, entrevista ficcional), há } \\
\text { também trabalhos com enfoque em } \\
\text { pesquisa-ação e pesquisa teórico- } \\
\text { analítica (PAULA, 2015). }\end{array}$ & $\begin{array}{l}\text { Análise: Dados coletados em dois } \\
\text { diferentes grupos, amostras } \\
\text { independentes, foi aplicada um } \\
\text { questionário com a escala RWA. Não } \\
\text { respeitando a abordagem qualitativa. }\end{array}$ \\
\hline $\begin{array}{c}5.3 . \\
\text { Compreensão } \\
\text { dos Resultados }\end{array}$ & $\begin{array}{l}\text { A compreensão dos resultados não pode } \\
\text { ser generalizada. Indica-se em estudos } \\
\text { do discurso da Teoria Crítica que se } \\
\text { utilize a análise hermenêutica-dialética } \\
\text { (BATISTA-DOS-SANTOS, ALLOUFA, } \\
\text { NEPOMUCENO, 2010), análise de } \\
\text { conteúdo ou análise crítica de discurso. } \\
\text { (SALLES, 2014). "A interpretação dos } \\
\text { fatos conduz à totalidade, sem que esta } \\
\text { seja, ela própria, um fato. Não há nada } \\
\text { socialmente fático que não tenha seu } \\
\text { valor específico nesta totalidade" } \\
\text { (ADORNO, 1980, p. 217 apud BATISTA- } \\
\text { DOS-SANTOS, } \\
\text { NEPOMUCENO, 2010). ALLOUFA, }\end{array}$ & $\begin{array}{l}\text { Análise: Os dados foram analisados } \\
\text { utilizando-se do programa de pacote } \\
\text { estatístico Minitab® } 16 \text {. Verifica-se se há } \\
\text { diferença no nível de autoritarismo, } \\
\text { identificado pela aplicação da escala } \\
\text { RWA, entre gerentes e trabalhadores do } \\
\text { nível operacional. A análise não } \\
\text { generaliza o resultado da pesquisa, } \\
\text { porém, nas limitações do trabalho o } \\
\text { autor deixa explicito sua } \\
\text { intencionalidade em generalizar. Tenta } \\
\text { explicar de maneira unívoca e } \\
\text { simplificada uma sociedade complexa. }\end{array}$ \\
\hline
\end{tabular}

Fonte: Elaborado pelos autores, 2020.

Para a análise, foi situado não apenas o que está explicitamente colocado pelo autor, mas também o que se compreendeu implicitamente, utilizando da escavação e comparação entre as partes do trabalho. Verificamos a coerência argumentativa, visto que a maior crítica aos estudos desta matriz teórica é seu caráter relativista e particular.

De maneira geral, como se pode observar no Quadro 2, o autor traz, explicitamente, poucos elementos que constituiriam um trabalho alinhado ao discurso da Teoria Crítica. De forma declarada, o autor se sustenta da teoria da Personalidade Autoritária de Adorno, buscando fundamentação no discurso da Teoria Crítica. Porém, através da análise de trechos como "subsidiar critérios para recrutamento e seleção para os indivíduos nas organizações" e "a pesquisa realizada foi descritiva, pois visa expor o fenômeno em detalhe", tornou-se evidente que sua opção pela Personalidade Autoritária se tornou uma opção metodológica, forçando uma adequação ao discurso da Teoria Crítica. 
Após analisar a coerência e a consistência, percebemos que o discurso se aproxima de uma discussão funcionalista. Em suas próprias conclusões o autor não explicita a crítica, menos ainda o caráter emancipatório que aparece em seu trabalho ligado a conceitos expostos, longe da práxis colocada pelos autores que o mesmo cita. A dificuldade do autor em trazer conclusões que contribuam com o campo de estudos na Administração resulta em parte da incoerência e inconsistência que seu trabalho apresenta. Foi analisado, na própria escrita do autor, uma dificuldade em conectar a abordagem do discurso da Teoria Crítica com as evidências empíricas. Observamos, neste sentido, que o caráter descritivo da análise se limitou a reforçar o que os números trazem.

Vale ressaltar, sobre tal questão, que o autor não precisaria fazer a opção por seguir o discurso da Teoria Crítica em um modelo "puro", pois a ciência social não se aplica em um universo neutro, porém precisaria explicitar sua decisão. O autor poderia ter trabalhado numa perspectiva híbrida, para não incorrer nos equívocos de coerência e consistência teórico-epistemológicos identificados.

Defendemos aqui o que Paula (2015) defende: que na prática da ciência há reconstruções epistêmicas desenvolvendo trabalhos que desenvolvem metodologias, bem como se ancoram em um hibridismo epistemológico. Compreendemos também que os fundadores das diversas abordagens, bem como as próprias matrizes epistêmicas, não conseguem abarcar toda a realidade que se apresenta para o pesquisador, ocorrendo o que Paula (2015) chama de incompletude cognitiva, quando o pesquisador aprimora epistemologias e metodologias em sua prática.

Após a análise apresentada, propomos dois caminhos que o autor poderia ter utilizado na condução de sua pesquisa. Tais propostas visam contribuir para uma maior coerência e consistência metodológica e epistemológica à investigação.

- Para que o trabalho tenha um alinhamento com o discurso da Teoria Crítica, torna-se necessário a complementação com a abordagem qualitativa, de forma a haver um maior aprofundamento da pesquisa e a compreensão das razões das diferenças apresentadas pelos resultados quantitativos em relação ao nível de autoritarismo dos gerentes das empresas industriais, tendo em vista a necessidade da abordagem histórica do objeto percebido, além da busca da emancipação.

- Mantendo apenas a abordagem quantitativa, se faz necessário explicitar que aquele instrumento de coleta de dados foi utilizado apenas por ser o mais adequado para medir o grau de autoritarismo, sem vincular o trabalho ao discurso da Teoria Crítica, classificando o trabalho sob a perspectiva funcionalista.

\section{Considerações finais}

Ao decidir por estudar determinados temas ou fenômenos sociais, pressupõese que o pesquisador seja movido por valores e crenças, alinhadas aos seus interesses de investigador, bem como orientados pela área de conhecimento em que atua. No âmbito dos estudos em Ciências Sociais, ainda que não expressamente reveladas, observamos as escolhas epistêmicas e metodológicas do pesquisador, as quais esperamos que sejam articuladas aos propósitos de sua pesquisa e às expressões e particularidades de seu objeto de estudo. Esses requisitos e 
expectativas evidenciam a legitimidade e a validade científica, consolidando resultados como contribuição ao avanço do conhecimento sobre um determinado campo ou tema de estudo.

A construção de tal coerência no caminho da produção científica, entretanto, nem sempre é simples, notadamente quando estudamos fenômenos sociais complexos cujas especificidades demandam técnicas e recursos de investigação que não seguem procedimentos objetivos, exigindo um desvelamento a partir da interpretação e da compreensão substantiva.

O enfrentamento a esse desafio, então, pode iniciar com a consciência, por parte do pesquisador, acerca de como "enxerga" o seu fenômeno de interesse em pesquisa e qual o seu propósito, sua interação e comprometimento em desvendá-lo. É a partir do seu posicionamento diante da realidade e das escolhas teóricas que o sustentam que o pesquisador pode seguir nas definições sobre como irá estabelecer a trajetória de sua investigação. Muitas vezes, esse alinhamento é sutil e complexo, fazendo com que o processo de pesquisa seja retomado em termos teóricos e epistemológicos, ou ainda, em seus métodos e aplicações práticas, para haver a consistência e a coerência necessárias aos requisitos da produção do saber científico.

São comuns os dilemas que estudantes e pesquisadores, em estudos organizacionais, vivenciam ao desenvolver pesquisas sobre fenômenos sociais, em termos de articulação entre métodos, teorias, paradigmas das Ciências Sociais; isso sem contar, por vezes, a dificuldade na delimitação e sustentação de um propósito/problema de pesquisa a partir de um recorte da realidade ou do contexto.

Considerando tais questões, este artigo buscou propor um modelo analítico para a condução de trabalhos científicos, no campo da Administração, à luz do discurso da Teoria Crítica, no intuito de contribuir para a promoção de coerência e consistência nas pesquisas acadêmicas elaboradas à luz da referida Teoria. Pretendemos, com este trabalho, apresentar elementos teóricos e alertar os pesquisadores sobre a importância do posicionamento diante da realidade social e das escolhas teórico-epistêmicas para a construção do conhecimento em Administração.

Ao ser utilizado na condução de trabalhos acadêmicos, o modelo analítico elaborado possibilita ao autor a identificação de elementos do trabalho e a verificação de seu alinhamento ao discurso da Teoria Crítica, abrangendo: paradigma, ontologia, epistemologia e metodologia. Sua utilização visa fortalecer o campo científico, pois no momento de se elaborar trabalhos científicos, sejam eles destinados a periódicos, eventos científicos, disciplinas, ou até mesmo para estudos de revisão sistemática na elaboração de dissertações e teses de doutorado, os autores terão em mãos um recurso de apoio com o qual poderão verificar a consistência epistemológica e metodológica do trabalho desenvolvido.

Sugerimos, como recomendação de estudos futuros, a ampliação deste modelo com a inclusão de novos elementos relacionados ao discurso da Teoria Crítica. Ainda, recomendamos a elaboração de recursos complementares, que auxiliem na análise da consistência e coerência epistemológica e metodológica para outros paradigmas/discursos da Administração, como o funcionalismo, interpretativismo, pós-modernismo e construtivismo. 


\section{Referências}

ADORNO, T.; HORKHEIMER, M. Dialética do esclarecimento: fragmentos filosóficos. Rio de Janeiro: J. Zahar, 1985.

ALLEN, A. Emancipação sem utopia: sujeição, modernidade e as exigências normativas da teoria crítica feminista. Novos Estudos, 103, CEBRAP, novembro 2015, p.115-132.

ALPERSTEDT, G.D.; ANDION, C. Por uma pesquisa que faça sentido. Perspectivas. São Paulo, RAE/FGV-EAESP, V.57, n.6, nov-dez 2017, p. 626-631. DOI: http://dx.doi.org/10.1590/s0034-759020170609.

ANDION, C. CAMINHA, D. O. Epistemologia da ciência da administração. 03 mar. 2017b, 28 jun. 2017. Notas de Aula.

BATISTA-DOS-SANTOS, A. C.; ALlOUFA, J. M. de L.; NEPOMUCENO, L. H. Epistemologia e Metodologia para as Pesquisas Críticas em Administração: Leituras Aproximadas de Horkheimer e Adorno. RAE. Revista de Administração de Empresas, v. 50, n. 3, jul-set, p.312-324, 2010. DOI: http://dx.doi.org/10.1590/S003475902010000300007.

BOTTOMORE, T. Dicionário do pensamento marxista. Zahar, 2012.

CARDOSO, A. L. J. Processo científico: a formação do pesquisador em Administração. Revista Pretexto, v. 16, n. 1, p. 99-116, 2015.

DEMO, P. Metodologia Científica em Ciências Sociais. São Paulo: Atlas, 1985.

DOMINGUES, J.M. Vicisitudes y possibilidades de la teoria crítica hoy: una conceptualización ecuménica. Revista de Ciencias Sociales, vol. 32, n.o 44, enerojunio 2019, pp. 103-122. DOI: http://dx.doi.org/10.26489/rvs.v32i44.5

FARIA, J. H. Análise crítica das teorias e práticas organizacionais. São Paulo: Atlas, v. 1, 2007.

FARIA, J. H.; MARANHAO, C. M. S. A.; MENEGHETTI, F. K. Reflexões Epistemológicas para a Pesquisa em Administração: Contribuições de Theodor W. Adorno. RAC. Revista de Administração Contemporânea (Online), v. 17, p. 642-660, 2013. DOI: http://dx.doi.org/10.1590/S1415-65552013000600002.

FARIA, J. H.; MENEGHETTI, F. K.; STEFANI, D. Razão tradicional e razão crítica: os percursos da razão no ensino e a pesquisa em Administração na concepção da teoria crítica. Revista de Ciências da Administração, v.18, n.45, p.140-154, Agosto 2016. DOI: http://dx.doi.org/10.5007/2175-8077.2016v18n45p140.

JAPIASSU, H. Introdução ao pensamento epistemológico. Rio de Janeiro: Francisco Alves, 1991.

KHUN, T. A estrutura das revoluções científicas. São Paulo: Perspectiva, 2015. 
MARANHÃO, C. M. S. A.; VILELA, J. R. X. Teoria crítica e Pesquisa Empírica: um Estudo sobre Theodor Adorno. In: XXXIV EnANPAD, 2010, Rio de Janeiro. XXXIV Encontro da ANPAD, 2010. v. 1.

MARANHÃO, Carolina S.; VILELA, J.R.P.X. A imanência entre a teoria crítica e a pesquisa empírica: contribuições para os estudos organizacionais. O\&S. Organizações e Sociedade, v.24, n.82, p.476-490, Jul./Set.2017. DOI: 10.1590/19849240826

MARCUSE, H. A ideologia da sociedade industrial: [o homem unidimensional]. São Paulo: Edipro, 2015.

. Eros e civilização: uma interpretação filosófica do pensamento de Freud. 8. ed. Rio de Janeiro: LTC, 2017.

MARX, K. Contribuição a crítica da economia política. 3. ed. São Paulo: Martins Fontes, 2012.

O capital: crítica da economia política: livro primeiro: O processo de produção do capital. São Paulo: Boitempo Editorial, 2015a.

O capital: crítica da economia política: livro segundo: o processo de circulação do capital. São Paulo: Boitempo Editorial, 2015b.

Manuscritos econômico-filosóficos. Coimbra: Edições 70, 2017a.

. O capital: crítica da economia política: livro terceiro: o processo global de produção capitalista. São Paulo: Boitempo Editorial, 2017b.

MARX, K.; ENGELS, F. A ideologia alemã. São Paulo: Boitempo Editorial, 2015.

Manifesto comunista. Pichilemu: El Marino Producciones, 2017.

MONJE-REYES, P.A. La Teoría Crítica como perspectiva de análisis de las relaciones de dominación y los procesos de descentralización en Chile. Cadernos EBAPE.BR, v. 13, no 2, Artículo 10, Rio de Janeiro, abr./jun. 2015. p.402-409.

NOBRE, M. A Teoria crítica. Zahar, 2004.

NOVAES NETTO, A.F. de; FERREIRA, V.C.P.; NOVAES, J.L.C.; NEIVA, D.S. A teoria crítica no estudo da administração. ReCaPe Revista de Carreiras e Pessoas, São Paulo, Volume VI, Número 03, Set/Out/Nov/Dez 2016. p. 282-302.

PAULA, A. P. P. Repensando os estudos organizacionais: por uma nova teoria do conhecimento. Rio de Janeiro: Editora FGV, 2015.

PINZANI, A. Teorias políticas tradicionais e teoria crítica. Lua Nova, São Paulo, n.102, p.57-91, 2017. DOI: http://dx.doi.org/10.1590/0102-057091/102

RUFFINI, M.L. El enfoque epistemológico de la teoría crítica y su actualidad. Cinta moebio, 60: 306-315, 2017. DOI: 10.4067/S0717-554X2017000300306 
SALLES, H. K. O. Conhece-te a ti mesmo: O Discurso da Avaliação em organizações sem fins lucrativos. Tese. Programa de Pós-Graduação em Administração - PPGA, Universidade Federal de Santa Catarina. Florianópolis, 2014.

SILVA, E. D.; COSTA, R. S. Uma reflexão epistemológica sobre o status científico da administração sob a ótica dos critérios de demarcação científica de Popper, Kuhn e Lakatos. Revista Ciências Administrativas, v. 25, n. 3, p. 1-15, 6 dez. 2019. Fundacao Edson Queiroz. http://dx.doi.org/10.5020/2318-0722.2019.9660.

WEBERING, S. I. Teoria crítica e teorias organizacionais: uma relação possível? Gepros: Gestão da Produção, Operações e Sistemas, v. 5, n. 4, p. 139, 2010. DOI: https://doi.org/10.15675/gepros.v0i4.890. 